\title{
ON THE CAUSES OF DIURNAL BODY TEMPERATURE RHYTHM IN MAN, WITH REFERENCE TO OBSERVATIONS DURING VOYAGE
}

\author{
Korehiro OGATA AND Takashi SASAKI* \\ Department of Physiology and Hygiene, Institute of Constitutional \\ Medicine, Kumamoto University, Kumamoto
}

It is an established fact that body temperature in man shows a diurnal variation with a maximum during the day and a minimum during the night. Causes of the fluctuation have long been studied in many ways from the last century downward by a number of investigators. Early in the current century BENEDICT $^{1)}$ observed influence of the inversion of the daily routine of life for periods of ten days and eight years, respectively, and demonstrated no tendency to an inversion of the temperature curve. Thus he reasonably supposed an inner rhythm resulting from habits of individual life, or even from habits long established in succeeding generation. Standing on a similar point of view, GESSLER ${ }^{2)}$ laid more stress on changes in the excitability of body functions, while VöLKER ${ }^{3)}$ thought much of external conditions which form determining factors in the milieu theory. Recently Aschoff ${ }^{4)}$ developed these concepts into circadian rhythm theory.

To this classical problem KLEITMAN has devoted himself and concluded that the diurnal temperature rhythm, once established, resists displacement, inversion, and, even more markedly, non-twenty-four-hour routines of living. ${ }^{5)}$ Under conditions of continuous daylight of the arctic summer, however, the body temperature rhythms appeared to become adapted rapidly to the environmental routine ${ }^{6)}$ which was recently confirmed by LoBBAN. ${ }^{7)}$ Observation during the polar night on the other hand was performed by LINDHARD ${ }^{8)}$ with satisfactory adaptation, too. Apart from these investigators, GIBSON ${ }^{9}$ and OSBORNE ${ }^{10)}$ demonstrated that the shifting of the daily routine as the result of time changes during the trip was accompanied by an apparent adjustment of the rhythmic temperature variation to the respective local time. The observation in the polar regions and during the trip might be in line with cosmic nature or milieu theory.

With all these theories the mechanism remains to be studied further, be-

Received for publication September 9, 1962.

* 緒方維弘, 佐々木隆. 
cause a careful review of the observations performed by the preceding investigators shows considerable individual variation of the subjects and everyone of the theories failed to give a clear-cut interpretation of the mechanism under overall conditions. An opportunity to make a few comments on this problem was given to OGATA, one of the authors, by his recent voyage fram Hamburg to Kobe, Japan. The present paper deals with the observations along with the results which have been obtained in our laboratory with particular reference to vestibular function.

\section{EXPERIMENTAL PROCEDURE AND RESULTS}

Rectal temperatures was not taken in all the experiments, partly because of the inconvenience of the procedure, but mainly because experience of many years has shown that, when proper precautions are taken, oral temperature run quite parallel to rectal ones.

\section{Diurnal Variation in Body Temperature during Voyage}

The author left Hamburg on November 29, 1961, aboard the Montevideomaru (D/W 11, 529; OSK) for Japan, passing through the North Sea, the Mediterranean and the Indian Ocean, and arrived in Kobe on January 16, 1962, as is shown in FIG. 1. The east-bound voyage resulted in a shorter periodicity of daily routine of 23 hours and 40 minutes. Oral temperature was taken every two hours as a rule, but in some critical cases frequent determination was made. Determinations of local time, latitude, longitude, the time of sunrise and sunset, and swell of the waves were all supplied by bridge officers. Swell is scaled into eight grades: 0 , no swell; 1 , slight swell; 2, moderate swell; 3 , rather rough swell; 4, rough swell; 5 , heavy swell; 6 , very high swell; and 7, abnormal swell. And wave is grouped, on the other hand, into ten grades: 0 , calm sea; 1 , very smooth sea; 2 , smooth sea; 3 , slight sea; 4 , moderate sea; 5 , rather rough sea; 6 , rough sea; 7 , high sea; 8 , very high sea; and 9, phenomenal sea. In FIG. 2, the grades of swell and wave were expediently taken as an overall index of the sea.

a) Influence of pitching and rolling. In FIG. 2, SS stands for seasickness and $(-)$ denotes being unaware of seasickness; ( + ) slight seasickness; (H) moderate seasickness with poor appetite; and (H) seasickness severe enough to be confined to bed. Dizzy means here having a sensation of dizziness even after pitching and rolling subsided. O.T. represents outdoor temperature and C. $T$. cabin temperature in centigrade.

The temperature curve on November 28 taken while anchoring showed a typical diurnal pattern with a morning rise, a plateau during the daytime and an evening fall. The boat set sail from Hamburg on the following day and was overtaken by a storm in the North Sea with an instantaeous wind velocity of 30 meters per second. The subject suffered from SS (H). Body 


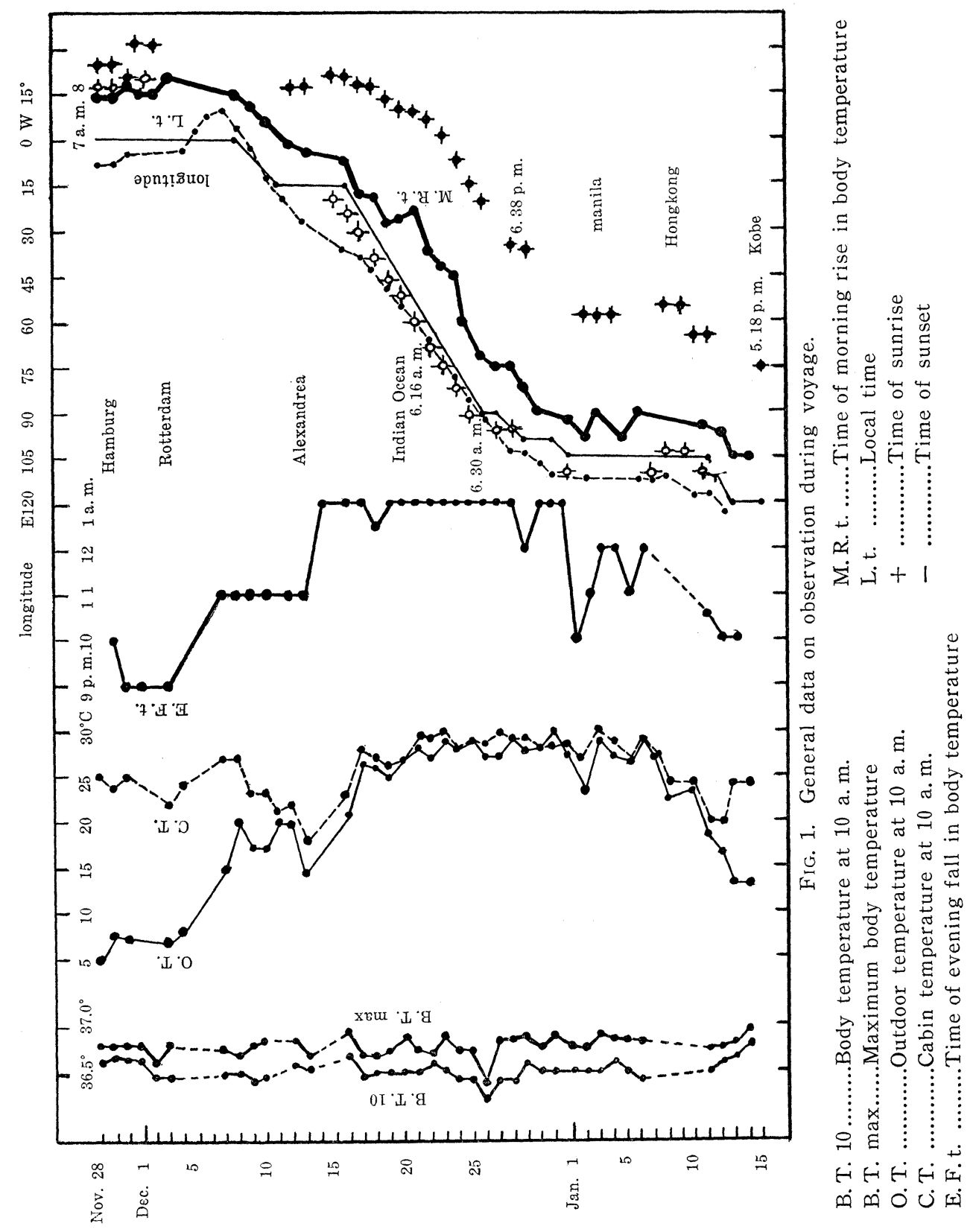




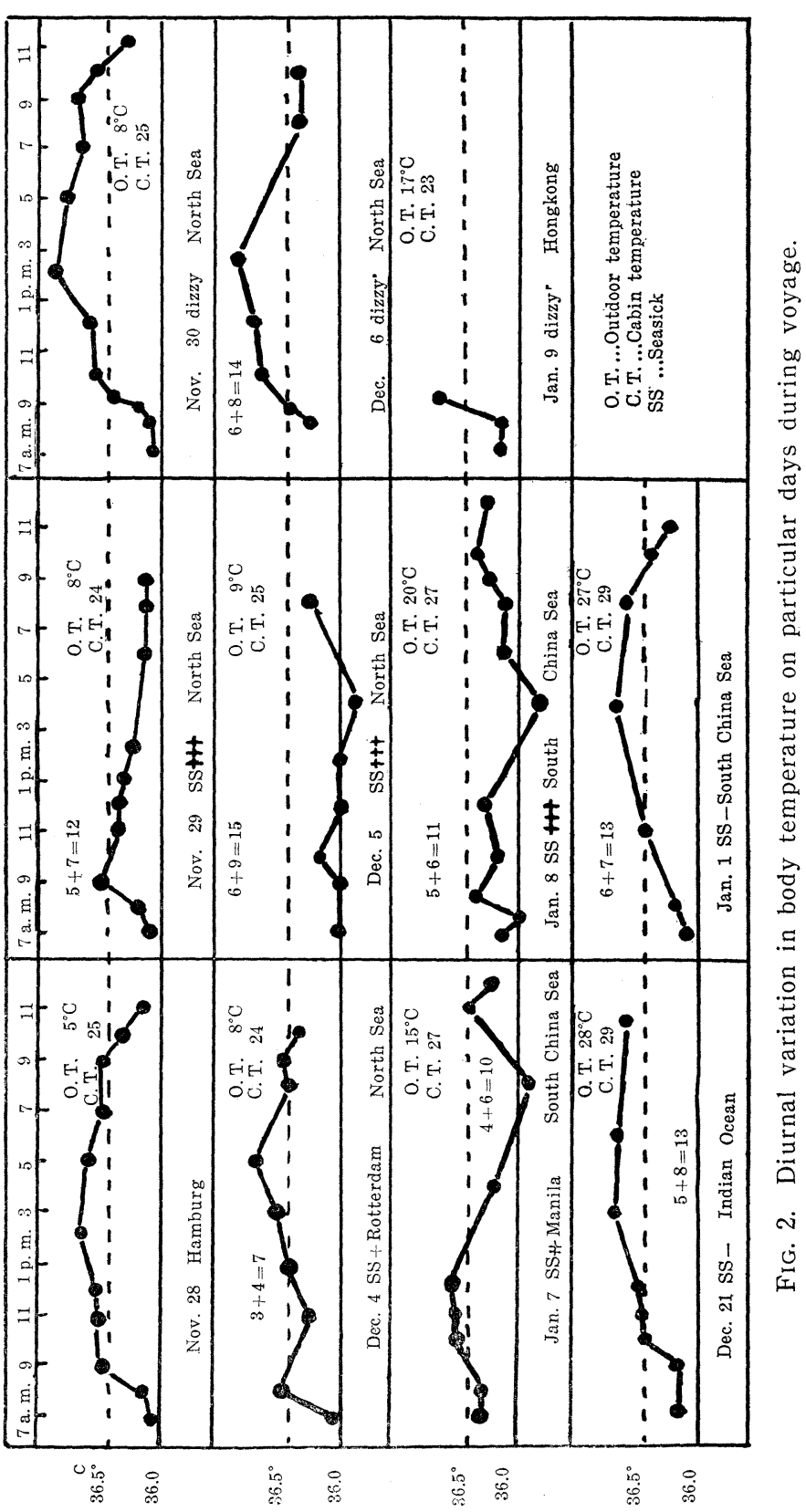


temperature on the storm-tossed day developed a morning rise at nine in the morning which was followed by a gradual fall throughout the day. Such a low level of body temperature always accompanied severe seasickness as is also illustrated in the curves of December 5, January 7 and 8, and the like. But "seasickness" was not absolutely related to "pitching and rolling" of a ship, to which the body seemed to adapt itself. On December 21 and January 1 , pitching and rolling was evaluated as 13 and yet the subject developed neither seasickness nor the lowering of body temperature. Therefore the lowering of body temperature is not absolutely attributable to the pitching and rolling, but to seasickness as a natural consequence of the former. It is to be noted that a rise in body temperature around nine in the morning failed to develop and that even in cases of lowered temperature level due to seasickness a trace of the morning rise was observed. During the stage of subjective feeling of seasickness after pitching and rolling subsided, the temperature showed a diurnal variation at a significantly higher temperature level. As seasickness was found to interfere with the regularity of body temperature rhythm, observations on these days are all excluded in the general data in which effect of transposition of the daily routine on the diurnal temperature curve is to be discussed.

Body temperature rhythm during vertigo caused by other mechanism than motion sickness is shown in FIG. 3. A pulmonary tuberculosis patient was treated with streptomycin in 1949 and when the total amount of streptomycin exceeded $35 \mathrm{~g}$ the patient complained of a feeling of vertigo, one of the side

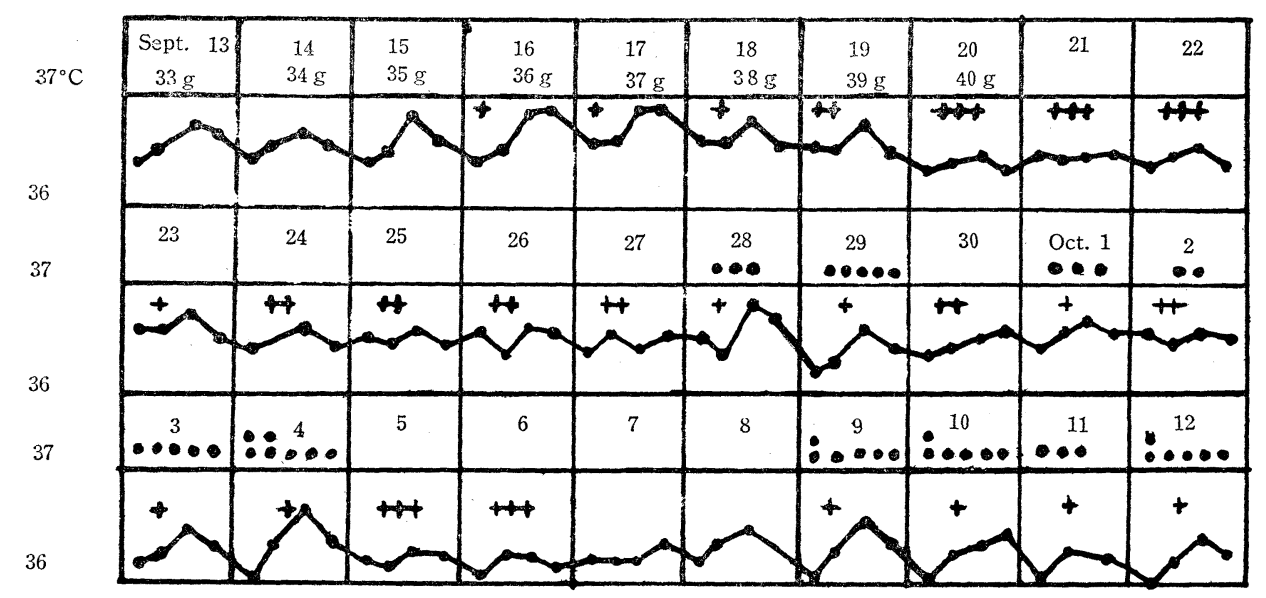

Fig. 3. Effect of vertigo on body temperature rhythm. Development of vertigo due to streptomycin and alleviation by antihistaminic administration.

$+++++\ldots .$. Degree of vertigo.

00 ............... Number of $10 \mathrm{mg}$ tablet of an antihistaminic drug.

$33-40 \mathrm{~g}$ Total amount of streptomycin injected. 
effects on the octave nerve. Showing scarcely any diurnal fluctuation, the curve of body temperature during the daytime remained practically at the same level as in the early morning. The basal metabolism fell down progressively to $29.6 \mathrm{kcal} / \mathrm{m}^{2} \cdot \mathrm{hr}$. But on administration of an antihistaminic drug vertigo was alleviated considerably, basal metabolism took an upward turn and body temperature regained diurnal fluctuation.

b) Time of morning rise in temperature. As is seen in FIG. 1 the time of morning rise in body temperature coincided best with the respective local time and less with the respective longitude, the time of sunrise or sunset.

c) Time of evening fall in temperature. Evening fall is defined here as a decided downward tendency of temperature in the evening as is illustrated in FIG. 2 at around 9 p. m. and afterwards on November 28 and 30. Day-today observation of the time of evening fall revealed a marked delay in developing the fall during voyage in a low latitude zone: in the Indian Ocean it was a general tendency that the fall was not recorded before $1 \mathrm{a}$. m. when the observation for the day was discontinued. The time of evening fall was found to coincide better with outdoor temperature than with cabin temperature.

d) Maximum body temperature. Body temperature at 10 a. m. accompanying morning rise (FIG. 1) maintained a level of $36.5^{\circ} \mathrm{C}$ with little day-to-day fluctuations, and so did the daily maximum of body temperature at about $36.8^{\circ} \mathrm{C}$. It is worthy of note that neither outdoor temperature nor cabin temperature affected these levels.

e) Transpacific observation. Diurnal rhythm of body temperature during voyage across the Pacific Ocean was observed on two male subjects (SASAKI ${ }^{11)}$ ). They started Yokohama in the evening (J.S. T.) on June 24, the international date line on June 29, a call at Honolulu on July 1, and arrived in San Francisco in the early morning (P.D.T.) of July 6. Consequently their daily routine has an average periodicity of 23 hours and 25 minutes. In this figure the temperature curves on each day were superimposed according to this periodicity, or local time, not to the usual twenty-four-hour day. The curves are far from typical temperature rhythm in spite of due consideration of seasickness, and the range of temperature fluctuation is considerably narrow. These findings suggest a transitory process of adaptation to a new periodicity and phase.

2. Some Observations on the Mechanism of Diurnal Variation

a) Effect of non-twenty-four-hour routines of living on body temperature rhythm. Two members of a family, T.S., male, aged 25, and H.S., female, aged 21, in preovulative stage, were the subjects of this study (SASAKI ${ }^{11)}$ ). The observation was performed in Kumamoto for 12 days, from December 30 to January 10, during which period programing of 11 days of sleep and wakefulness activity schedule were made by a combination of one 24-, three 28-, two 24-, three 28- and one 24-hour days, with a complete reversal of activity rhythm on the fifth and sixth days. During waking hours the subjects were 
engaged in sedentary work in a room with artificial illumination.

The body temperature curves on successive days are superimposed according to both calendar day and to routine of living, as illustrated in FIGS. 4A and $4 \mathrm{~B}$, respectively. In FiG. $4 \mathrm{~B}$ body temperature at any time of day varied considerably from day to day and general trend of diurnal variation was hardly recognized, while in FIG. 4A the variation was much smaller and typical diurnal rhythm was repeated day after day in accord with solar movement, irrespective of irregular routine of life: "morning rise" was observed regularly at 8 or 9 a.m. though it did not necessarily correspond to morning hours of their
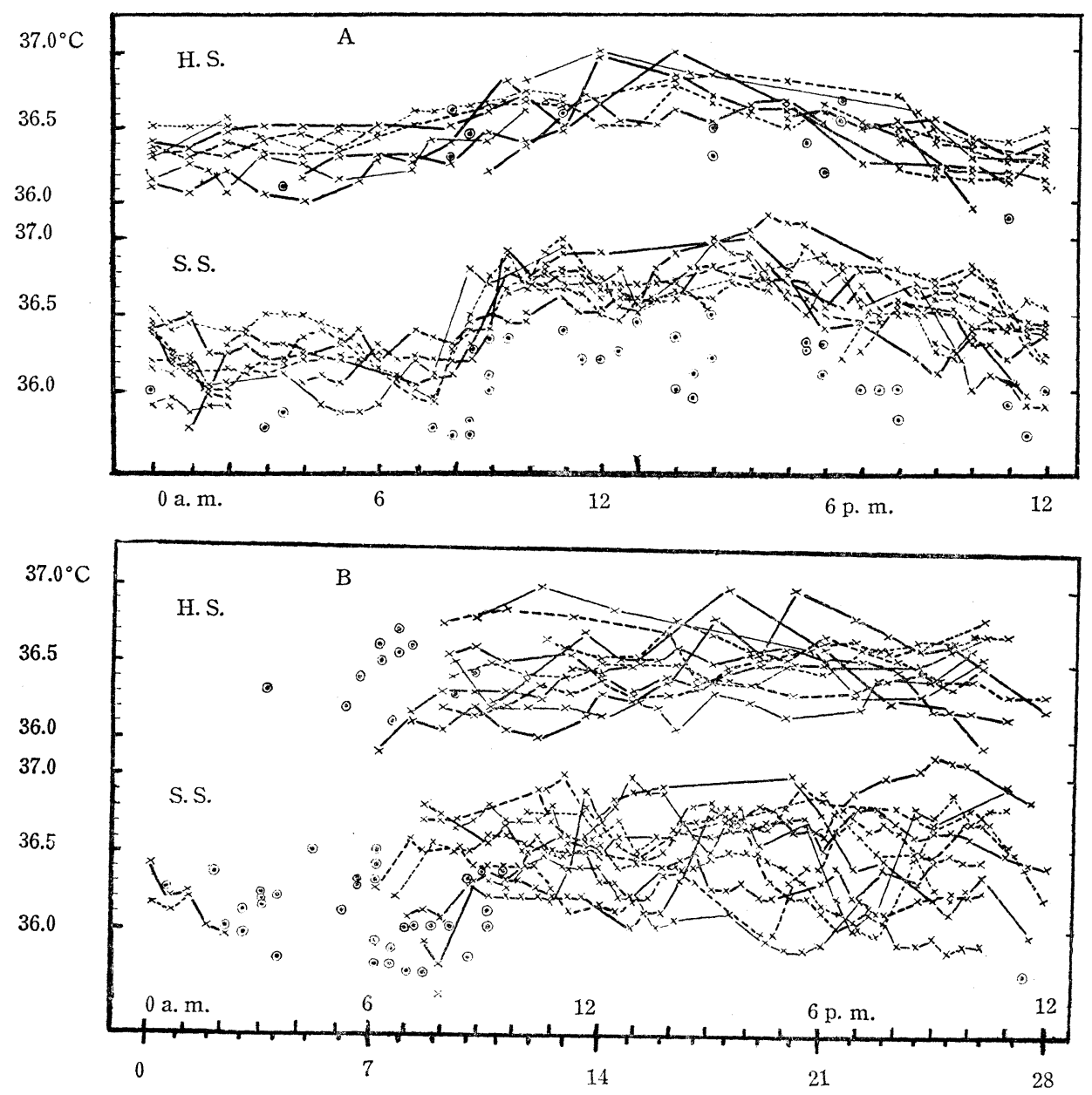

Fig. 4. Body temperature rhythm during prolonged and inverted routines.

A: Superimposition according to calender day.

B: Superimposition according to schedule of living. $\times$.............Sitting. $\quad$............ Lying in bed. 
routine life. A high temperature level was maintained during the daytime which was followed by "evening fall". But the time of the onset of evening fall was not uniform and the temperature curves in the evening hours developed a considerable day-to-day difference. A slight rise in temperature was sometime produced after meal but nor essential, while the morning rise was inevitably brought about and had nothing to do with food intake.

b) Effect of irregular routine of life for years on body temperature rhythm. The experiment was performed in collaboration with Dr. E. UeNo in our laboratory. Diurnal variation of body temperature was observed on five door-keepers of a factory, whose daily routine was subjected to rotation of three 8-hour shifts for several years, 12,11,10,5 and 4 years, respectively. In two subjects working for 12 and 11 years, body temperature in the afternoon during rest or sleep became low, while in the other subjects the plateau was shown in the afternoon as in the ordinary working hours. A rise in temperature during the night shift was found in all five subjects.

\section{Observation of Diurnal Body Temperature Rhythm under the Ground}

FIG. 5 shows diurnal variation in body temperature observed on three male laboratory workers ( $N, 33$ years of age; K, 28; and S, 26) in a coal-mine $320 \mathrm{~m}$ under the ground, where possible influences of cosmic agents are considered to be excluded $\left(\mathrm{SASAKI}^{11)}\right)$. The experiment was performed in a room primarily

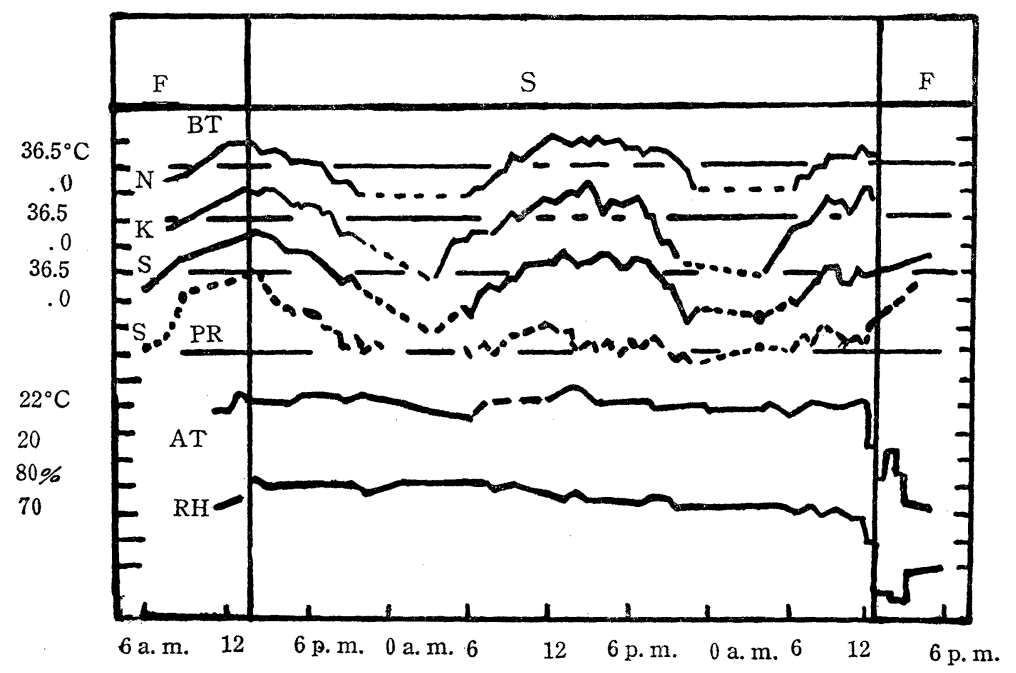

FIG. 5. Body temperature rhythm under ground.

S........Stay in a coal mine $320 \mathrm{~m}$ under the ground.

F.........Surface of the earth.

BT......Body temperature.

PR......Pulse rate.

AT......Ambient temperature.

RH......Relative humidity. 
reserved for first-aid station. The room was walled with thick concrete and the environmental conditions were kept quite constant at a room temperature of $22 \pm 1{ }^{\circ} \mathrm{C}$, and relative humidity of $70-80 \%$. Except slight hum of voices outside of the room during shifts at 6,14 and 22 hours, the room was deserted and enjoyed an absolute isolation from the external world, on which the milieu theorists lay much stress. For 47 hours beginning at 2 p.m. on April 5 oral temperature was taken every 30 minutes. All of the subjects showed a typical diurnal pattern with regular periodicity and any change was not demonstrated in the temperature curve.

\section{DISCUSSIÖN}

The primary point of discussion is what serves as pacemaker to diurnal rhythm of body temperature. Our observations point out that the morning rise is an essential feature of the rhythm, and the subsequent rise in body temperature during the daytime is subject to casual influences. To cite an example, the latter is apt to be suppressed by seasickness and the like, while the former is so persistently established that a trace of it never fails to develop even in a very severe case of seasickness. As to the effect of vertigo caused by other mechanism than motion sickness, vertigo due to a side effect of streptomycin resulted in elimination of diurnal rhythm by a lowering of body temperature in the daytime along with a marked depression in basal metabolism. Recovery from vertigo following administration of an antihistaminic agent is accompanied with increased basal metabolism and normal temperature rhythm with a considerable diurnal range.

Since vertigo is developed mainly by abnormal vestibular functioning, it is highly probable that the morning rise in body temperature be closely related to vestibular functions. As an important factor in diurnal variation of body temperature, another evidence is furnished by children, in favor of probable relationship with vestibular function. KLEITMAN et al. ${ }^{12)}$ gave statistical evidence as to establishment of the adult type of diurnal temperature curve during the second year of child's life, when the nervous system develops remarkably and a child learns to walk. Consequently SASAKI ${ }^{11)}$, one of the authors, observed the diurnal temperature rhythm on 127 deaf-mutes, aged 8 to 13 , who are too often complicated with some defects in the vestibular functions. Nothing remarkable was noticed in temperature pattern on any of them. However, special consideration should be paid to the fact that the subjects observed were all in chronic stage and they might have established some sort of compensation for the accompanying functions. It is similarly circumstanced in the experiment during voyage when the subject became adapted to seasickness and the body temperature was not lowered. Elevation of diurnal temperature rhythm during prolonged sensation of dizziness after a storm is 
compatible with the observations of $T$. OGATA ${ }^{13)}$ that vertigo caused by visual distortion, is entirely different from the case of streptomycin treatment, and has no inhibitory effect on oxygen consumption at the least, but there is a trace of tendency at work which will bring about elevation in metabolism.

Based on these findings it may be reasonable to presume that a so-called pacemaker in the mechanism of diurnal body temperature rhythm is closely related to vestibular functions, and further to "morning rise", the development of which was found to be in good agreement with local time during voyage. The time of "evening fall", on the other hand, varied with the latitude or outdoor temperature, showing a marked delay in hot environment. Even in a hot environment experienced on the Indian Ocean the level of maximum body temperature was not raised at all and this confirms that all the observations were made within the range of normal temperature regulation.

Good agreement of morning rise with local time naturally leads to a notion of its synchronization with daily routine of life. As was demonstrated by SASAKI in his experiment of prolonged and inverted daily routines, the time of morning rise is not dependent on the hours of activity schedule, but on the hours of calendar day, the time of evening fall is not uniform, and a slight temperature rise following food intake is not always produced. Consequently such factors as ambient temperature, muscular activity, food intake and the like are of minor importance. They may affect minor details of the diurnal pattern and nothing more.

The next problem is how long and how firm the morning rise persists. Observation of diurnal body temperature rhythm on door-keepers, living in a way of irregular routine of life for years, showed that some distortion of temperature rhythm was presented only in those who followed the routine more than 10 years. Therefore negative findings by BENEDICT ${ }^{1)}$ on inverted routine for 8 years is justly accepted. Moreover, in disturbing the temperature rhythm quite an irregular rotation of routine as our subjects performed would become a stronger factor than his monotonous inversion of routine. Thus a possibility to overcome the persistence was demonstrated only in such an extreme case. Here diurnal rhythm of body temperature might be compared to motion of a pendulum with a huge bob. Once it is set in motion little energy is required to keep the pendulum vibrating, but in order to modify its movement in any way considerable amount of energy is to be given, particularly at the point of vertical position where momentum is the largest, and this point might be comparable to the time of morning rise.

The above-mentioned conception is in line with a school of attaching importance of inner rhythm. In regard to cosmic causes, Flockungszahl of blood advocated by TAKATA ${ }^{14}$ ) was not affected when observed $200 \mathrm{~m}$ under the ground, and chemical tests initiated by PICCARDI ${ }^{15)}$ was also found least influenced $340 \mathrm{~m}$ under the ground ${ }^{16)}$. So our observations of body temperature 
$320 \mathrm{~m}$ under the ground may be regarded to be performed to the exclusion of various cosmic factors, and judging from environmental conditions of the room the experiment is also interpreted to furnish negative proof to support milieu theory.

Such being the case the last problem to be discussed is why the persistent inner rhythm defying every attempt to change its regularity follows, without any appreciable resistance, daily shift of local time during the voyage from Hamburg. But in the other case of voyage over the Pacific poor adjustment to a new periodicity and phase was given. So the speed on a cruise seems to be responsible for the difference in adaptation. The length of a day in a boat is 23 hours and 40 minutes in the former case and 23 hours and 25 minutes in the latter, a reduction of 20 and 35 minutes, respectively. So it is quite natural that a difference of four hours from the usual length of a day is far from establishing synchronization of sleep and wakefulness with the 28-hour schedule of living. Travelers who made an east-bound flight across the Pacific often refer to their experiences for the first several days in the United States of the difficulty of getting to sleep at night and subsequent drowsiness in the daytime. This might come, though not confirmed yet definitely at this time, from desynchronization of body functions from the new phase of routine of life. It may therefore be presumed that there exists a certain limit to the non-twenty-four-hour schedule of living to which the temperature rhythm can adjust itself with little resistance, and the range of deviation is supposed to be considerably narrow, some 20-25 minutes a day at the outside.

Some differences resulting from age in diurnal curve of body temperature was found by MIYAZAKI ${ }^{17)}$ in our laboratory. In the aged group the morning rise develops much earlier than in the adult controls. It may occur even when some of them are still in bed. The time of evening fall is advanced, too. Thus a general tendency toward a shift to early hours was confirmed in the aged.

\section{SUMMARY}

As a part of studies on the physiological mechanism for the establishment and maintenance of diurnal body temperature rhythm, observation to reveal possible factors affecting the development of temperature pattern was made with particular reference to observations during voyage and the length of daily routine.

1. The time of morning rise in body temperature coincided best with the respective local time, and less with the respective longitude, the time of sunrise or sunset.

2. During severe vertigo due to seasickness, the temperature rise in the daytime was suppressed remarkably, but the morning rise hardly disappeared 
under any circumstances.

3. High ambient temperature during the voyage exerted no influence on the level of temperature plateau in the daytime, but it delayed the night fall.

4. Any change in the diurnal fluctuation was not observed in the temperature curve taken in a cell $320 \mathrm{~m}$ under the ground.

5. Based on observation of daily pattern of body temperature during prolonged or inverted daily routine, irregular shift of daily routine for years and during vertigo caused by medicine, it is highly reasonable to assume that the mechanism is primarily attributable to the inner rhythm of functional pattern which has been acquired mainly through vestibular functions. Besides, it may be presumed that there exists a certain limit to the non-twenty-four-hour schedule of living to which the body temperature rhythm can adjust itself.

Grateful acknowledgement is made to Mr. M. YAMAGUCHI, captain of the Montevideo-maru (OSK), and his crewmen for their cooperation.

\section{REFERENCES}

1) Benedict, F.G.: Studies in body-temperature. I. Influence of the inversion of the daily routine; the temperature of night-workers. Am. J. Physiol. 11 : 145-169, 1904.

2) Gessler, H.: Untersuchungen über die Wärmeregulation. III Mitteilung. Die täglichen Schwankungen der Körpertemperatur. Pflügers Arch. 207 : 390-395, 1925.

3) VölKeR, H.: Über die Tagesperiodischen Schwakungen einiger Lebensvorgänge des Menschen. Pflügers Arch. 215 : 43-77, 1927.

4) Aschoff, J.: Symposia on quantitative biology. 25: 11, 1960.

5) Kleitman, N.: Sleep and wakefulness. Chicago: Univ. of Chicago Press, 1939.

6) Kleitman, N. AND Kleitman, E.: Effect of non-twenty-four-hour routines of living on oral temperature and heart rate. J. Appl. Physiol. 6: 283-291, 1953.

7) Lobban, M.: Studies on physiological diurnal rhythm in polar regions. Cited by Edholm, O. G. in Physiology in the polar regions. Nature 178: 954-956, 1956.

8) LindHARD: Meddel. om Grönland 44, 1917.

9) Gibson, R.B.: The effects of transposition of the daily routine on the rhythm of temperature variation. Am. J. Med. Sci. 129: 1048-1059, 1905.

10) Osborne, W. A.: Body temperature and periodicity. J. Physiol. 36(6) : Proc. 3941, 1908.

11) SASAKI, T.: Some experiments on the mechanism of the diurnal variation in the human body temperature, with particular reference to some influence of the labyrinth. Taishitsu Igaku Kenkyusho Hokoku (Bull. Res. Inst. Diath. Med.) 3 : 262270, 1953. (Japanese)

12) Kleitman, N., Titelbaum, S. and Hoffmann, H.: The establishment of the diurnal temperature cycle. Am. J. Physiol. 119: 48-54, 1937.

13) Ogata, T.: Gaseous exchange during vertigo caused by turning of the visual fleld. Taishitsu Igaku Kenkyusho Hokoku (Bull. Res. Inst. Diath. Med.) 5: 39-42, 1954. (Japanese)

14) Takata, M. And Dohmoto, M.: Über eine neue Methode zur Bestimmung der “Flockungszahl” des Blutes. Tohoku J. Exp. Med. 28 : 522-536, 1936.

15) Piccardi, G.: Kosmische Phänomene und Bioklimatologie. Wien. Med. Wschr. 
$108: 126-130,1958$.

16) Ogata, K., Sasaki, T., Ueno, E. and Tsukamoto, S.: Relazione delle cause cosmiche variazioni diurne nella temperatura corporea osservate nelle miniere. Minerva Medica, 53(37) : 1435-1436, 1962.

17) Miyazaki, M.: unpublished. 